Review

\title{
A Systematic Literature Review of Successful Implementation of Industry 4.0 Technologies in Companies: Synthesis of the IPSI Framework
}

\author{
Olivier Cardin (D)
}

check for updates

Citation: Cardin, O. A Systematic Literature Review of Successful Implementation of Industry 4.0 Technologies in Companies: Synthesis of the IPSI Framework. Appl. Sci. 2021, 11, 8917. https:// doi.org/10.3390/app11198917

Academic Editor: Silvio Abrate

Received: 20 August 2021

Accepted: 13 September 2021

Published: 24 September 2021

Publisher's Note: MDPI stays neutral with regard to jurisdictional claims in published maps and institutional affiliations.

Copyright: (C) 2021 by the author. Licensee MDPI, Basel, Switzerland. This article is an open access article distributed under the terms and conditions of the Creative Commons Attribution (CC BY) license (https:// creativecommons.org/licenses/by/ $4.0 /)$.
LS2N UMR CNRS 6004, IUT de Nantes, Nantes University, 2 Avenue du Pr J. Rouxel, Carquefou, 44470 Nantes, France; olivier.cardin@univ-nantes.fr

Featured Application: Practitioners have missed a clear methodology to introduce Industry 4.0 in companies. Based on a systematic literature study, a new framework was synthesized to help them in creating implementation processes.

\begin{abstract}
The Industry 4.0 paradigm refers to a large set of technologies that will transform the way that the manufacturing industry will perform. Nowadays, those technologies and the potential benefits they offer are not fully understood and mastered by companies, and the propagation of the associated concepts is slow. However, in the past few years, some successful implementations of Industry 4.0-compliant technologies have been seen emerging in the literature. A systematic literature study has been conducted to identify the suggested methodologies for successful implementations. Following this analysis, identified patterns are synthesized as an implementation framework denoted as IPSI (Identification-Preparation-Simulation-Implementation). This framework was synthesized so as to be used for the first implementation of technologies in a company, thus increasing the chances of acceptability of those technologies. Three case studies, concerning three different technologies in three different manufacturing fields, were chosen to be confronted by the framework and its validity on the global manufacturing field is discussed.
\end{abstract}

Keywords: Industry 4.0; holonic manufacturing system; additive manufacturing; reconfigurable manufacturing system; industrial implementation

\section{Introduction}

Whether it is called "Cyber-Physical Production Systems", "Industry 4.0" or "Factory of Future" [1], an important evolution, driven by innovative information and communication technologies (ICT), is currently on the edge of happening in industry. The introduction of new technologies and concepts are meant to induce a major change in the way the manufacturing systems are controlled. Among others, the main challenges industry is facing concern data protection and data security, integration in the value chain, the loss of control in internals, and the human-machine hierarchy [2]. These subjects have been dealt with for more than a decade now, but an empirical assessment can allow a consensus: penetration of Industry 4.0 principles in industry is currently very low.

In 2017, a study on Czech industry [3] illustrated the feelings of industrial companies about these principles. After interviewing more than 150 companies, the main reason given by the companies as to why Industry 4.0 principles were not applied in their context was a lack of knowledge about the topic, and half of the companies did not even intend to try and integrate these new principles. Even if the perimeter of the study was relatively small, the results were similar to figures that can be found from other sources (e.g., only $32 \%$ of US companies were using or were on the edge of using Industrial Internet of Things technologies as of 2017 [4]). These results are symptomatic of a reality that everyone is 
facing every day: the current period is still one of dissemination of the concept-proof of feasibility and persuasion of decision-makers, rather than broad and rapid dissemination.

This statement is even more true when dealing with SMEs. The investment costs and the industrial risk of deep transformations of production equipment are major issues for this type of industry [5]. The UK recently launched an innovative program, targeted at SMEs, aiming at disseminating the concepts via low-cost implementations of simple prototypes in their environments [6]. This project is intended to have many benefits in the mid-term for companies, as it is meant to answer to some of their main concerns about Industry 4.0 technologies [7].

However, some interesting implementations of these technologies can still be found in the literature, in various domains. Published documents about case studies generally exhibit a progressive methodology for gaining the trust of an industry toward a new technology before actual implementation. This work intends to synthesize this literature through a systematic literature study, in order to be able to provide a general framework, providing guidelines for future researchers or practitioners intending to introduce new technology to a company that has no prior knowledge in the field. Once this first implementation is successful, it is rational to believe that the company will be willing to extend it and be significantly more proactive in the integration of other technologies as its productive tools.

This framework is composed of four main stages, namely Identification, Preparation, Simulation and Implementation, and is denoted as IPSI. It is intended to be used for the first implementation of technologies in a company; thus, increasing the chances of acceptance of the technologies. Three actual case studies, concerning three different technologies in three different manufacturing fields are then confronted with the framework to validate it.

The article is structured as follows. The first section introduces a global overview of Industry 4.0-related technologies and the lack of methodology to support decision makers in implementing these technologies in the field. In the second section, a systematic literature review is presented, which allows to extract literature related to frameworks, and an analysis of these frameworks, which exhibited the five main features that such a framework should incorporate. The third section presents the IPSI framework and details the 10 steps required for successful implementation. The final section provides confrontation of the framework with industrial cases, namely in additive manufacturing (AM) for aeronautics, reconfigurable manufacturing system (RMS) for automotive and holonic manufacturing systems (HMS) for logistics.

\section{Context and Problems}

The development of Industry 4.0 is meant to have an important impact on all levels of the supply chain: procurement, logistics, warehousing, production, and even fulfillment [8]. This development is closely related to the development of innovative technologies, both for the process itself and in the information and communication field. However, this development is not trivial to implement in industry. The introduction of RFID technology, for example [9], is associated with many difficulties (the authors identified 18, from top management to process operators), which make this evolution difficult in the field.

Three main categories of technologies were identified by [3], namely digital mesh (device mesh, ambient user experience, 3D printing machines), smart machines (information of everything, advanced machine learning, autonomous agents and things) and a new IT reality (adaptive security architecture, mesh app and service architecture, IoT architecture and platforms). The most promising technologies were identified a few years ago when the authors of [10] identified the main technological pillars of Industry 4.0, which were later confirmed in [11-14]. These technologies were classified as emerging technologies in [15] and are still currently envisioned in the Industry 4.0 trajectory $[16,17]$. Recent reviews of their potential impacts on future industrial systems are provided below:

- $\quad$ Big data and analytics [18];

- Autonomous machines [19]; 
- Advanced simulation towards digital twins [20];

- Industrial IoT [21];

- Cloud manufacturing [22];

- Additive manufacturing [23];

- Augmented reality [24].

By implementing all these technologies, greater assurances of safety, security, scalability, and reliability are expected, therefore exhibiting the need for open interfaces, modularity, interoperability, and verification [25]. All these notions are relatively new to end-users, which makes their adoption slower.

In addition, the conclusions drawn from practitioners when implementing former Industry 3.0 innovative technologies (automation and robotics to name a few) still make sense: it is the case study that implies the success of new technology introduction, not the opposite. In the same way that the automatization of some manual manufacturing operations can be a disaster from many aspects (repeatability, quality, productivity among others), the same drawbacks are to be expected in terms of the application of an inappropriate technology in the field. Furthermore, the complexity that is naturally induced by the introduction of a new technology implies the need for continuous technological project management, aiming at the success of integration of all its aspects (technical, organizational, etc.). This critical success factor was identified in [26] as the need for a careful choice of the leader of Industry 4.0 technology implementation. This task, which was highlighted as a new potential Industry 4.0-oriented job profile by the authors of [27], and was denoted as a digital development specialist, will necessarily handle multiple skills and expertise.

Based on these statements, it is clear that a generic methodology to assist this digital development specialist in the integration of new technology, independent from the targeted technology, is missing.

\section{Literature Review}

This section introduces the systematic literature review process that was conducted in order to determine the main characteristics of the different frameworks presented in various contexts in the literature. Herein, the main question this literature review intends to answer is: "What are the generic frameworks intended to guide Industry 4.0 implementation in companies for practitioners?".

\subsection{Structure of the Review}

The field of Industry 4.0 technology implementation is vast. While a large bibliography is dedicated to actual implementation of technologies (at various technology readiness levels, TRL), publications have recently appeared that introduce implementation frameworks for a more or less large range of industries. The issue that was faced in this review is the genericity of the keywords, which can be used in many different ways by authors. Therefore, in order to identify those publications, a systematic literature review (SLR) was performed. The chosen methodology is presented in [28] and consists of five steps:

1. Definition of the review scope: this step is used to define an appropriate perimeter of the scope and orientation of the review;

2. Conceptualization of the topic: this step intends to define the keywords that will be used in the next step, searching for articles;

3. Literature search: this step includes the choice of the source of information and the design of the queries in accordance with the previously defined topics;

4. Literature analysis and synthesis: this step shows the process of inclusion/exclusion of the results of the requests, and a categorization of the reasons that led to this result;

5. Research agenda: the last step consists in an analysis of the content of the included articles, showing the evidence retrieved from the review. 


\subsubsection{First Step: Definition of Review Scope}

This first step is especially well suited for literature reviews on a large scope, where a horizontal search on a large range of topics is needed. It consists in defining the perimeter of the review and highlighting the main keywords. Here, the objective is rather oriented towards a vertical search, in order to identify the frameworks that are actually related to the work. The review scope here is directly connected to the previously defined problems. The objective is to detect the few articles that deal with a generic framework or methodology to implement Industry 4.0 technologies in companies from the whole set of articles dealing with only the implementation of one of those technologies.

\subsubsection{Second Step: Conceptualization of Topic}

The topic was decomposed into three necessary sub-topics: (i) the environment; (ii) the contribution; and (iii) the generalization.

The environment is mainly built around the Industry 4.0 paradigm; however, some authors might use the terms "smart factory", "intelligent manufacturing", or "smart manufacturing" to illustrate the same concept.

The contribution is meant to address the implementation of new technologies, integration of those technologies in a manufacturing environment, or the transformation from a classical manufacturing system to an Industry 4.0-compliant one. These three terms were, therefore, addressed.

The desired articles were meant to introduce a new framework or methodology, generalizing implementations. Therefore, those two terms were added to the topic.

\subsubsection{Third Step: Literature Search}

In order to address a wide range of valuable contributions, the Scopus database was chosen. The topics mentioned above were searched in titles, abstracts, and keywords in the whole database, limiting the subject area to engineering, business, computer science, materials, energy, and the environment (which constitute the main pillars of Industry 4.0 technologies). Finally, only journal and proceeding papers in the English language were accepted in this search in order to consider only internationally recognized work. In details, the Scopus request was:

(TITLE-ABS-KEY ("smart factory" OR "intelligent manufacturing" OR "smart manufacturing" OR "Industry 4.0") AND TITLE-ABS-KEY (implementation OR integration OR transformation) AND TITLE-ABS-KEY (framework OR methodology)) AND (LIMITTO (SUBJAREA, "ENGI") OR LIMIT-TO (SUBJAREA, "COMP") OR LIMIT-TO (SUBJAREA, “BUSI") OR LIMIT-TO (SUBJAREA, "MATE”) OR LIMIT-TO (SUBJAREA, “ENER") OR LIMIT-TO (SUBJAREA, "ENVI")) AND (LIMIT-TO (LANGUAGE, “English")) AND (LIMIT-TO (SRCTYPE, “j”) OR LIMIT-TO (SRCTYPE, “p”)).

This initial search resulted in a total of 1024 records.

\subsubsection{Fourth Step: Literature Analysis and Synthesis}

The 1024 records obtained from Scopus were imported into Rayyan QCRI [29], a free online tool that can be used by researchers to assist in a systematic literature review. It allows to label each record with reasons to include or exclude articles from the final review. A first analysis, based on only the metadata of the records (title, abstract, keywords) was performed thanks to the filtering options in Rayyan. For records with ambiguous results, a manual check of the full text version was performed in order to guarantee accuracy of the analysis. This manual step was performed on approximately $15 \%$ of the all records.

Several exclusion criteria were defined:

- Wrong publication type: special issue proposals, preface of proceedings, etc. A total of 24 records were excluded based on this criterion;

- Background articles: records where Industry 4.0 terminology is only used as the background or for future research directions. A total of 749 records were excluded based on this criterion; 
- $\quad$ Early TRL technologies: records introducing innovative technologies, only available at low TRL levels and/or in a laboratory proof-of-concept. A total of 55 records were excluded based on this criterion;

- Implementation examples: records stating the application of one specific technology in industry, but not general. A total of 36 records were excluded based on this criterion;

- Implementation architectures: records exhibiting a framework of implementation of a specific technology in industry, without enough generalization. A total of 49 records were excluded based on this criterion.

Finally, a total of 12 papers were included in the review.

\subsubsection{Fifth Step: Research Agenda}

In this step, a detailed analysis of the 12 records determined in the last step was introduced. The records were all published in 2019 and 2020, in manufacturing or computerscience-oriented journals and conferences. For each of these records, an evaluation of strengths and weaknesses of the proposals was performed, in order to infer some good practices to integrate in the framework presented in the next section. Table 1 summarizes the main elements of the following detailed analysis.

Table 1. Literature framework analysis summary.

\begin{tabular}{cccc}
\hline Reference & Field of Application & Range of Application & Methodology Description \\
\hline$[30,31]$ & IIoT & Whole project lifecycle & None \\
{$[32]$} & Industrial cyber-security & Technical study & None \\
{$[33]$} & All industrial fields & Whole project lifecycle & Detailed for managers \\
{$[34]$} & Data management in SMEs & Whole project lifecycle & Basic for practitioners \\
{$[35]$} & Innovative ICT technologies in industry & Technical study & Basic for managers \\
{$[36,37]$} & Innovative ICT technologies in industry & Technical study & Basic for practitioners \\
{$[38,39]$} & All industrial fields & Technical study & Basic for managers \\
{$[40]$} & Evolution of SMEs & Whole project lifecycle & Detailed for managers \\
{$[41]$} & Lean based organizations & Whole project lifecycle & Application specific \\
This Study & All industrial fields & Whole project lifecycle & Detailed for practitioners \\
\hline
\end{tabular}

\subsection{Detailed Analysis}

The framework presented in $[30,31]$ is focused on the problem of Industrial Internet of Things integration in industry. This framework was developed from multiple application studies, which provides some value to the proposition. Indeed, it covers all the aspects such a project should address. However, the methodological aspect is not precisely defined, which makes it barely usable by practitioners. The most interesting aspect is that it shows that it is necessary to have multi- and inter-disciplinary studies during a project and constant communication with management, in order to establish the validity of the required investments.

Several frameworks also point out pertinence to adopt a step-by-step transformation of the manufacturing system: the authors of [32] mention, for example, an evolution before a revolution in their conceptual scheme of Industry 4.0 (Figure 1).

From a larger point of view, the authors of [33] introduced a generic methodology framework defined as seven phases, oriented towards managers:

1. Definition of company vision and strategy for the implementation of Industry 4.0;

2. Identification and description of company processes;

3. Implementation of fully-fledged information system (e.g., ERP/ERP II) and manufacturing data;

4. Digitalization of collected data, creation of digital twins and modification or purchase of machines;

5. Implementation of horizontal integration;

6. Data analysis and vertical integration; 
7. Self-managed production and logistics.

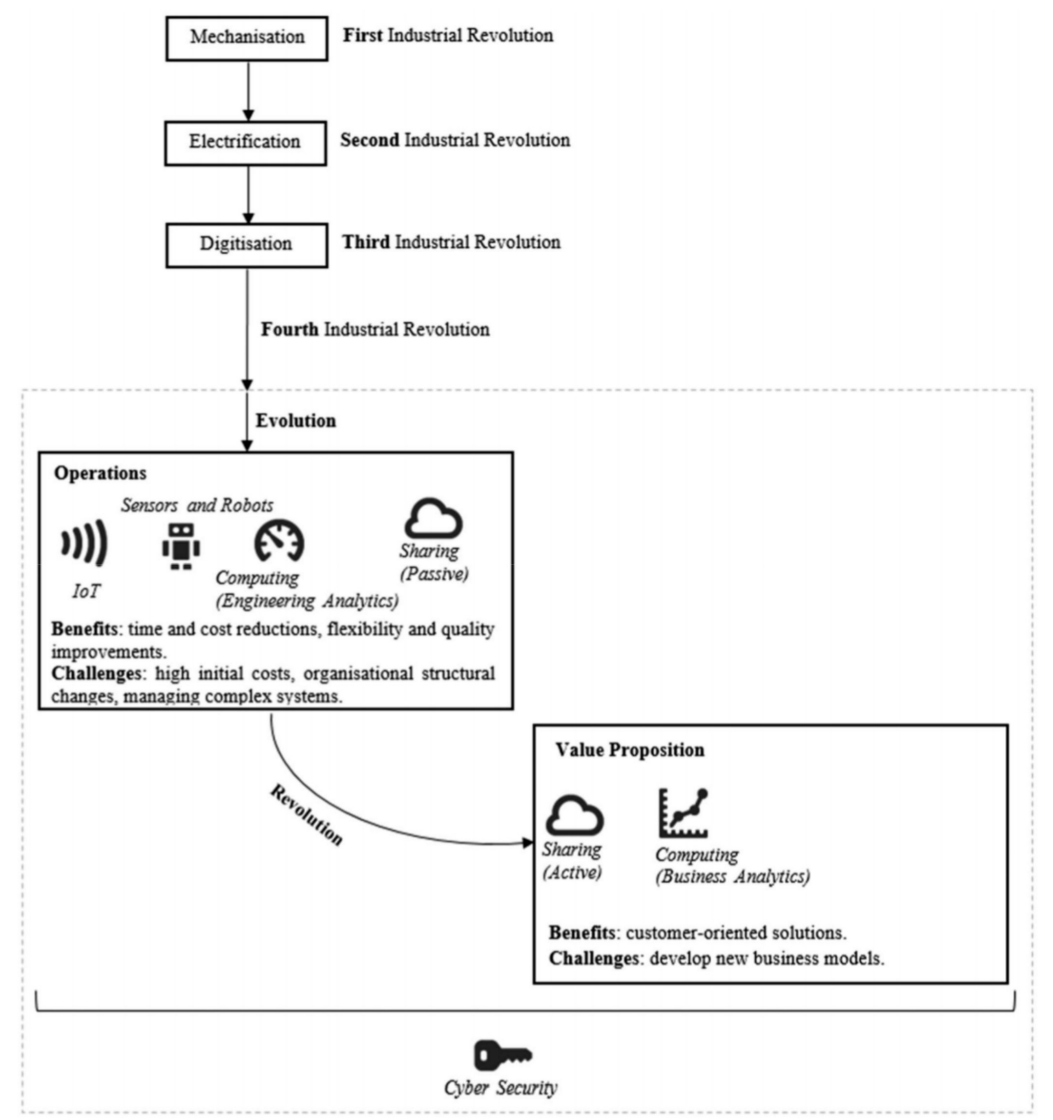

Figure 1. Conceptual scheme of Industry 4.0 evolution/revolution. Reprinted with permission from [32]. Copyright 2020 Taylor \& Francis.

This framework articulates different targets and objectives, but misses some guidelines for a practical implementation.

Another framework was introduced in [34], which was designed with the objective of integrating a specific technology, in order to assist practitioners in introducing smart manufacturing in SMEs. This framework was based on four major steps:

1. Identify available manufacturing data;

2. Readiness assessment of data-hierarchy steps;

3. Smart manufacturing tailored vision development;

4. Tools and practices identification.

This framework actually mostly focuses on the data management aspect, which constitutes one specific facet of new technology introduction. Therefore, its genericity needs to be extended in order to encompass any type of technology.

From a more detailed perspective, a three-stage evolution was defined by [35] for a better adoption of Industry 4.0 technologies. Based on four basic, mainly focused on the data management aspect, the authors illustrated how the characteristics of a system can be progressively enhanced in order to reach (fully or partially) the level of performance that is expected.

These frameworks are interesting from a macro perspective, but, again, do not provide any methodological guidelines for a practitioner.

In order to integrate technical and management aspects, several frameworks insist on the necessity of including a simulation-based evaluation of the models in order to retrieve the necessary KPI for management-oriented decisions. In this way, the framework presented in $[36,37]$ was mostly focused on the technical aspects of the transformation. 
The framework was denoted as a development framework (Figure 2) and illustrates an implementation loop based on the evaluation of simulation campaigns. The models and simulation technologies that are listed in this framework encompass only informationoriented technologies, which is a partial view when considering the whole set of available Industry 4.0 technologies. In the same way, the logical model presented in [38] clearly exhibited the need for simulation studies during the implementation process, and placed them at the core of the process. The notion of digital twins [39] is referenced here as a way to connect these simulation studies with actual data coming from the system.

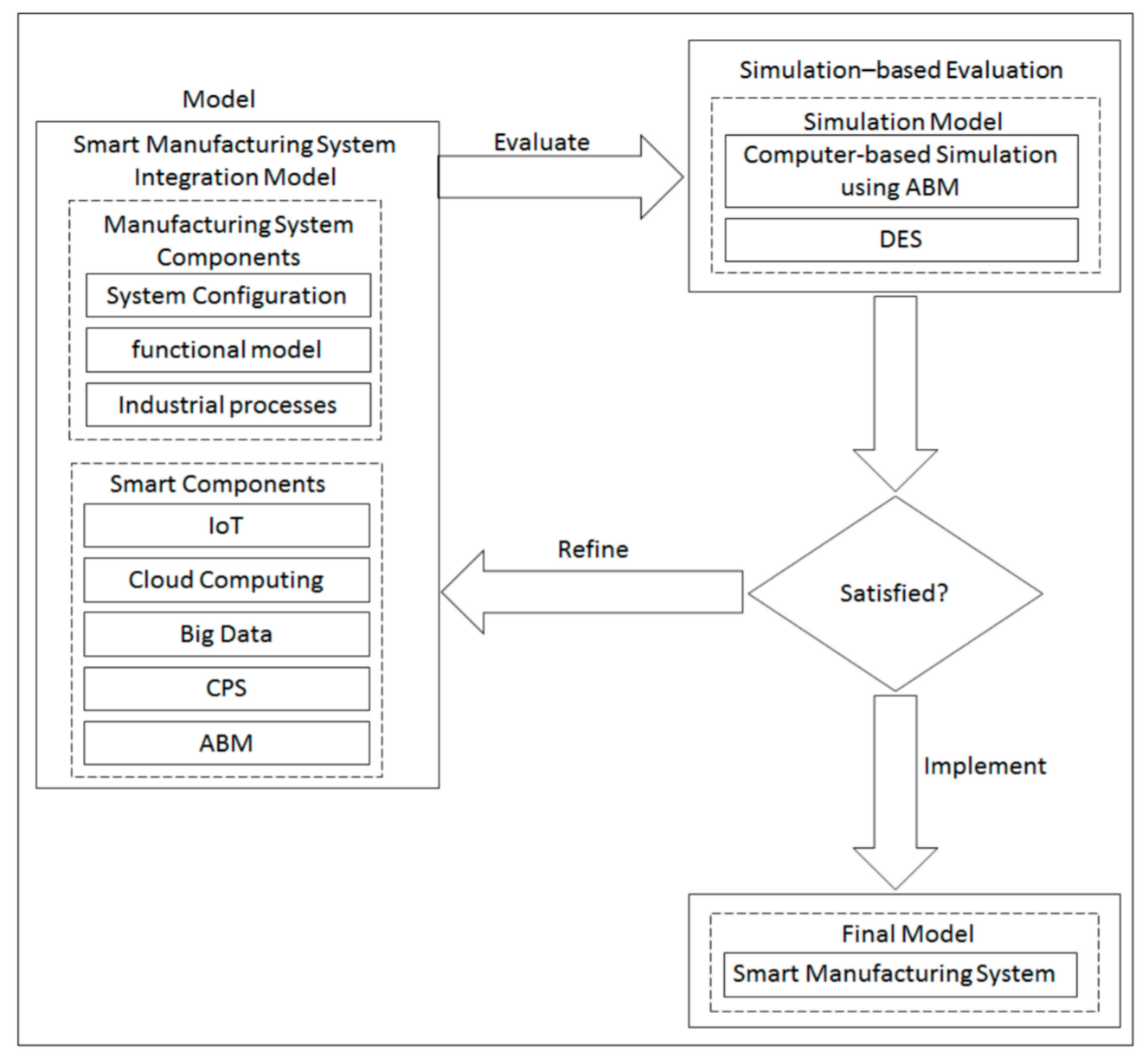

Figure 2. Smart manufacturing system development framework. Reprinted with permission from [37]. Copyright 2019 SAI.

Another aspect of the methodology deals with the definition of enhancement levers. The authors of [40] designed an approach, SME-oriented, that incorporated an initial analysis of brakes and levers that can be used to remove those breaks (Figure 3). These levers of acceleration are meant to become the key factors in the whole approach, driving changes through the definition of appropriate indicators. The rest of this approach is SME-specific and not detailed at sufficient a level for being a generic enough methodology.

Finally, the framework presented in [41] exhibited an interesting decomposition of the framework into four phases, namely Conceptual, Preparation, Implementation, and Completion. This framework was actually designed as a methodological framework for practitioners, focused on the integration of advanced concepts of Lean and Blue Ocean Manufacturing (Lean-BOM). As a matter of fact, this framework cannot be used as is for other implementations, as some of the steps are very specific (Gemba Walk for example).

As a synthesis of this analysis, the five best practices that were especially highlighted by these 12 frameworks are: 
1. An iterative and step-by-step transformation of the manufacturing systems;

2. Decomposition of the framework into four phases;

3. Integration of the management layer at different stages of the framework;

4. Mandatory definition of levers of enhancement;

5. Importance of a specific phase of simulation-based evaluation.

The next section introduces the IPSI framework, incorporating all these features with the objective of becoming an actual methodological framework for practitioners aiming at implementing new Industry 4.0 technologies in industry.

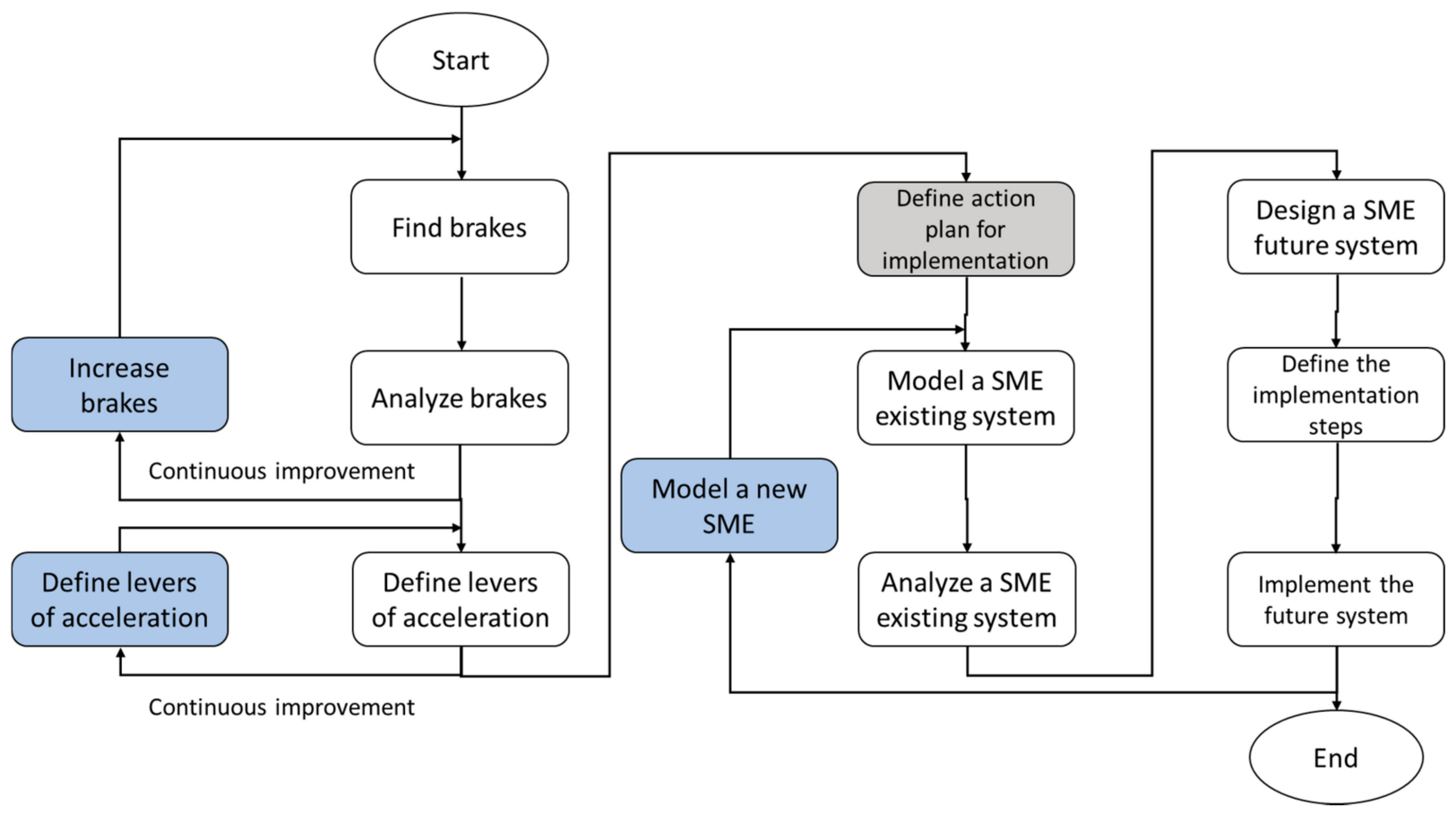

Figure 3. Approach of Industry 4.0 implementation in SMEs. Reprinted with permission from [40]. Copyright 2019 Elsevier.

\section{Synthesis of Literature: Introduction of the IPSI Framework}

This section intends to introduce the IPSI framework, providing a step-by-step methodology, enabling researchers and integrators to better prove the potential benefits and impacts of Industry 4.0 technologies to a company without any prior knowledge in the field. This framework is fully technology-independent and can therefore be applied for any of the innovative technologies expressed in the previous section. The framework is presented in Figure 4. It is composed of four main stages (namely I, P, S and I), that constitutes the outline of this section. In each subsection, an extensive explanation of each step is given.

\subsection{Stage I: Identification}

The first stage of the framework concerns the decision-makers of a company.

In the first step, it is necessary to define which lever the company would like to integrate in its system. This lever is intended to enhance one or several characteristics of the system. Some levers can, for example, be derived from the definition of the pillars of smart manufacturing [42]:

Pillar 1: Manufacturing technology and process-Reconfigurability [43];

Pillar 2: Materials-Smart materials [44];

Pillar 3: Data-Conditional maintenance [45];

Pillar 4: Predictive engineering - Cloud manufacturing [46];

Pillar 5: Sustainability—Products remanufacturing [47];

Pillar 6: Resource sharing and networking-Flexibility [48]. 


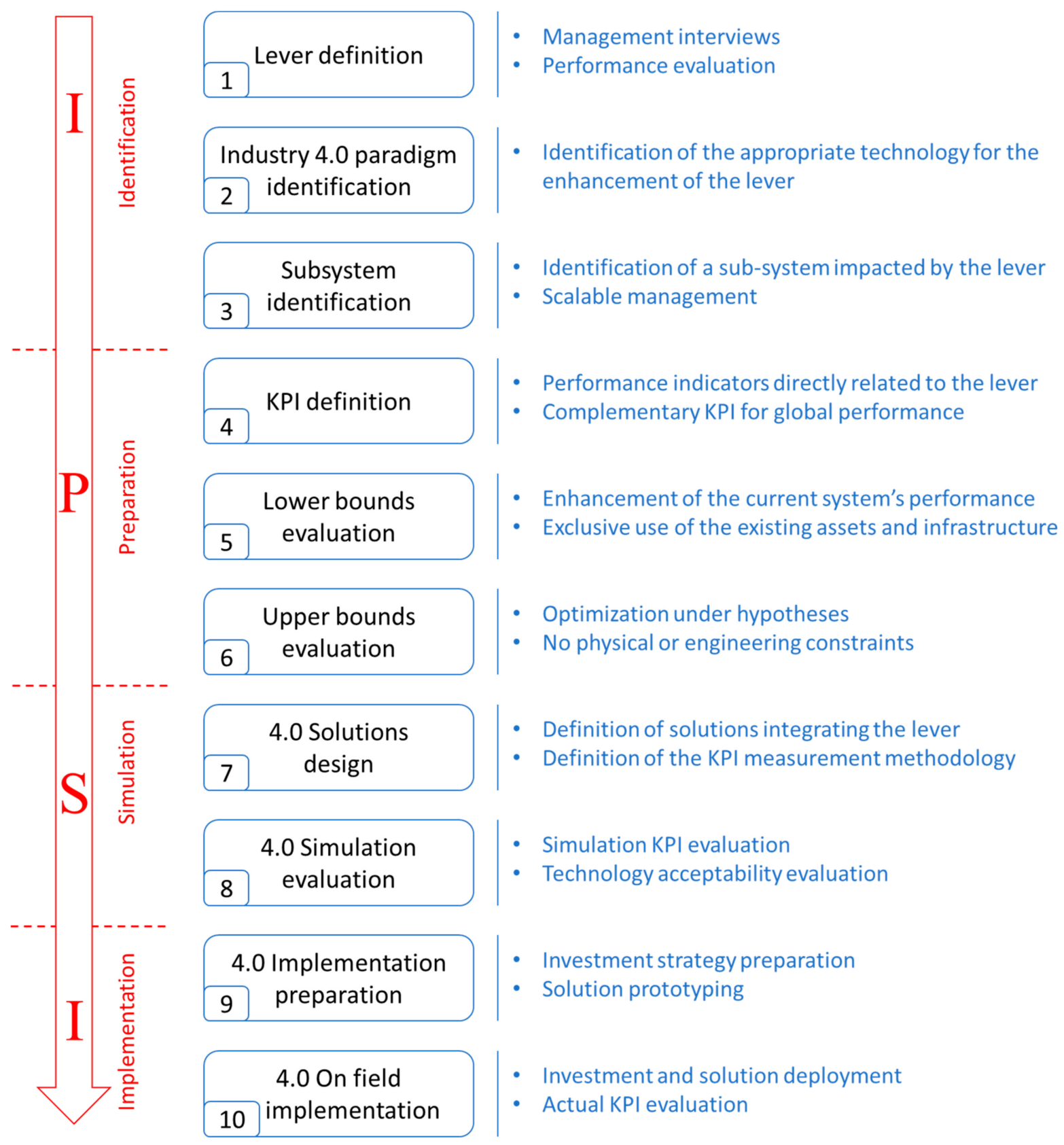

Figure 4. IPSI framework description.

This first step is very strategic, and needs to be perfectly aligned with the actual needs of a company in terms of its employees and partners.

The second step is the identification of the paradigm and associated technologies that can enhance the performance of the company towards the previously defined lever. If this step could be technically executed later, it is important to start disseminating the main principles of this solution in the direction of the decision makers: potential investments generally need to be planned over a long period of time, sometimes recruitment need to happen, etc., and this information will contribute to the success of the last steps. The technologies expressed in the previous section are relevant candidates for this step.

Third step is again a strategic decision. It is generally doomed to failure to try and make the entire manufacturing system evolve in a single step. On the contrary, it is usually better to focus on a representative sub-system: investments are usually less important, risks are seen as lower by decision makers, development time is shorter, and if well executed, 
the results can still be evaluated very positively. Scalability of the chosen solution is also an important advantage for the success of this step.

\subsection{Stage P: Preparation}

This second stage is meant to be executed with production managers, who have knowledge of the current behavior of a system (actual or how it should be) as well as its desired behavior. Formalizing their expertise is a crucial stage of the procedure, as it defines the way the new solutions will be evaluated.

The fourth step of the overall procedure, and the first step of the second stage, consists in defining the key performance indicators (KPI) related to a subsystem and to the previously chosen lever. The KPI needs to be measurable in both the current situation and the situation with the new implemented technology. It is also necessary to define a set of reference scenarios that will be used in the next steps.

The fifth step consists in an evaluation of the lower bound of the study. This lower bound is calculated or measured in the system in its current configuration. It is meant to represent the performance of a system in an unsatisfying configuration, and therefore express the minimal performance any solution should attain.

The sixth step consists in evaluating an upper bound of the performance of a system. In this step, a model with a large number of simplifying assumptions is built. These assumptions are generally about physics or engineering limitations and are made to evaluate the best performance that any solution could attain. The evaluated scenario is necessarily the same as the one used in the fifth step to obtain consistent results for comparison.

\subsection{Stage S: Simulation}

At the end of this stage, the feasibility of the solution is evaluated and a go/no-go decision will be made by production managers, based on simulation results that will be obtained as well as the perceived perspectives.

The seventh step consists in designing a prototype application, including the lever technology chosen in second step. The most important part of this design is to closely work with the production managers in order to enhance the understanding of the lever and avoid a feeling of misunderstanding regarding the lever. It can be necessary to include training courses, demonstrations, on other case studies or testimonies from other companies to speed up the inclusion of production managers in the design loop. Once they are fully integrated and the design is almost complete, the topic of the KPI needs to be reevaluated. Indeed, some technologies might induce such a large change in the production process where the indicators cannot be evaluated in the same way as in the upper and lower bound evaluations (steps five and six).

The eighth step starts by designing a simulation prototype of the solution, aiming at providing the relevant KPI in a reasonable time for evaluation. To enable comparison, the established scenarios for the lower and upper bound evaluations need to be simulated. Further scenarios can also be added to this evaluation in order to investigate new functionalities that were not possible with the previous implementation.

\subsection{Stage I: Implementation}

This final stage induces a progressive shift between production managers and company decision-makers, including some interactions between them.

Ninth step is intended to prepare implementation. The differences between the actual implementation and the simulation study need to be assessed in order to determine the best implementation protocols. A real-size prototyping of the solution needs to be performed in order to validate the simulation results and validate the feasibility of on-site implementation. The development phase of this prototype is a convenient moment to start training potential developers and integrators of the company to use this new technology and to the way in which it is implemented properly. From this validation, the last elements 
needed are the preparation of the investments needed and the deployment calendar of the actual implementation.

Last step consists in actual implementation of the solution on site. This implementation is generally used for evaluating the accuracy of the simulation results and reassure decisionmakers. However, for what constitutes the first implementation of an Industry 4.0-oriented tool in a company, this first implementation also serves as a showcase for the rest of the company. It is necessary from this point to address the possibility of extending this technology to the other sub-systems of the company.

\section{Applicability on Various Technologies}

This section first introduces a comprehensive description of the methodology used for demonstrating the range of applicability of the IPSI framework. Then, three case studies depicted in recent literature are presented with respect to the IPSI framework.

\subsection{Evaluation Methodology}

Evaluating such a methodology is a difficult task, as it is generally not directly connected to identified performance indicators. Furthermore, such implementations are generally "one-shots", and concurrent uses of different methodologies for comparison purposes are generally impossible. The choice made in this study was to analyze different studies found in the literature that successfully integrated Industry 4.0 tools in a company, chosen because of their variety of technologies and application fields. One study was on reconfigurable manufacturing system in the automotive industry, one study was on additive manufacturing in aeronautics, and one was related to the use of multi-agent systems in a mail sorting center. As far as the authors know, no other publications were found documenting in enough detail the implementation process, except in the field of industrial agents [49]. However, as this technology has already been covered, these were not considered here.

The objective is to present how these very different studies actually follow the IPSI framework. The variety of tools and application fields demonstrate the pertinence of the approach and its genericity for future deployments. Each study will be presented in the next sections, directly following the framework. At each step, numbered I1 to I3, P4 to P6, S7, S8, I9, and I10, the corresponding elements in the study are exhibited, as summarized in Table 2. The objective is not to emphasize the results of the studies themselves, but rather to focus on the methodology described. The first study is about manufacturing system designs, the second one is about product design, and the final one is about real-time control of manufacturing systems.

Table 2. Case study summaries.

\begin{tabular}{|c|c|c|c|}
\hline IPSI Steps & Manufacturing Systems Design $[50,51]$ & Product Design [52] & Manufacturing Control $[53,54]$ \\
\hline $\mathrm{I} 1$ & Variability of the demand & Complexity reduction & Variability of the demand \\
\hline $\mathrm{I} 2$ & RMS & Additive manufacturing & HMS \\
\hline I3 & One assembly line & One single part & $\begin{array}{c}\text { One robotic } \\
\text { pick-and-place station }\end{array}$ \\
\hline P4 & $5 \mathrm{KPIs}$ & 4 KPIs & 2 KPIs \\
\hline P5 & Dedicated manufacturing system & Classical design and machining & $\begin{array}{l}\text { Expert-based model evaluation } \\
\text { by simulation }\end{array}$ \\
\hline P6 & Zero reconfiguration time & $\mathrm{N} / \mathrm{A}$ & $\begin{array}{c}\text { Zero operation times and infinite } \\
\text { buffer sizes }\end{array}$ \\
\hline S7 & Exact methods for optimization & DBAM methodology & Heuristics definition \\
\hline S8 & $\begin{array}{l}\text { Evaluation of optimization results by } \\
\text { discrete-event simulation }\end{array}$ & Low cost materials & $\begin{array}{l}\text { Discrete-event } \\
\text { simulation-based evaluation }\end{array}$ \\
\hline I9 & Investment strategy definition & Use of actual machine & $\begin{array}{l}\text { Emulation-based } \\
\text { software development }\end{array}$ \\
\hline $\mathrm{I} 10$ & $\begin{array}{c}\text { Integration of reconfigurability in future } \\
\text { line design }\end{array}$ & $\begin{array}{c}\text { Design framework integration in } \\
\text { design office }\end{array}$ & $\begin{array}{l}\text { Extension of the control to } \\
\text { interconnected services }\end{array}$ \\
\hline
\end{tabular}




\subsection{Reconfigurable Manufacturing System for Car Manufacturing}

This study deals with the deployment of RMS in the automotive industry, namely at the PSA company [50]. This study was conducted as a PhD, co-supervised by the company itself and a laboratory. In the context of assembling various engines, where the pressure on the cost of the manufacturing system is strong, the double objectives are to satisfy customer demand while using an optimized means of production. Hence the need to define the best strategy design and reconfiguration of the manufacturing system, in order to respond to a variable demand, in the objective of incremental investment [51].

Step I1: the lever definition was defined in a coordinated way. A questionnaire was established in order to gather as many opinions as possible in terms of the expectations of decision-makers. The main lever identified here deals with some unpredictable variability in the demand of different references of manufactured products.

Step I2: The paradigm that was identified here was the RMS. Indeed, the culture of flow shops in the automotive industry, the volume of production, and the possibility of producing in (smaller and smaller) batches makes it possible to investigate the possibility to stop the system, reconfigure it, and run production with an interesting return on investment. More precisely, this study deals with reconfigurable assembly systems (RAS).

Step I3: The automotive industry generally implies large factories, including several autonomous workshops. In this context, the choice was made here to focus on an assembly line for combustion engines, representing twenty stations, automatic or collaborative, making the operator and robotic resources work in the same space. Two types of engines are assembled on this line: a three-cylinder petrol engine and a four-cylinder diesel engine. Each station contains between one and thirteen assembly tasks, performed sequentially or in parallel, in a time less than or equal to the rate. The tasks are carried out by robotic arms or an operator.

Step P4: A set of five performance indicators were identified [50] to discriminate the reconfiguration solutions: scalability, defined as the product between a factor representing the range of reconfiguration and the size of the volume increment, time and cost factors, and a parameter corresponding to the number of modules added in the system to achieve the increment; convertibility, defined as the ability of the system to switch quickly between the production of different products within the same product family or between product families; modularity, which corresponds to the property of the system to be divided between sub-units and to integrate new sub-units; integrability, which corresponds to the ability to include new components on the line using adapted interfaces; and customization, which assesses the ease of switching from one product to another through the selection of appropriate elements of the system. A weighted function enables to calculate a single score for every solution. The weights are determined during interviews with the decision-makers.

Step P5: The configuration giving the lowest scores on each of the previous indicators was determined as the initial configuration of the line before the study. The production lines were organized in a continuous flow (flowshop layout), consisting in a succession of workstations between which products circulate on fixed conveyors. Each workstation is dedicated to a sequence of assembly tasks and a type of product. The product characteristics, tasks to be carried out, and the allocated resources are fixed before the line is started. The model is centered on the workstation, which is characterized by the resources, assembly tasks, and its location in the plant.

Step P6: The upper bound of the solution was determined with an evaluation of the potential sequence of configurations giving the best performances with a reconfiguration time set equal to 0 . This solution, physically impossible, provides the optimal performance that can never be reached by an actual solution. Its utility is based on the comparison that is done with the proposed reconfigurations, in order to better evaluate the pertinence of the propositions.

Step S7: When integrating mobile or moveable resources, it is necessary to determine their allocation to the workstations, which was solved by optimization, with the objective of minimizing the manufacturing time of the product list. Exact methods were used for 
the exact resolution of small problems, while approximate methods were used to solve NP-hard problems. Several different configurations were generated, which were evaluated by simulation in next step.

Step S8: A coupling between the optimization module used in S7 and programmed in OptQuest and Simul8 simulation models developed in this step enabled to determine the best configurations to be used. Several KPIs were defined for each scenario, among which the usage rate of resources, movement rate of mobile resources, and number of assembled engines on the whole horizon (6 days usually). Each configuration is compared to the same scenario simulated with fixed conveyors (P5) to evaluate performance enhancement.

Step I9: The implementation preparation step is represented in this case by the definition of the investment strategy. The solutions that were found in the previous steps exhibit the need for investing in mobile resources along the evolution of demand, and a ramp-up strategy needs to be defined along with the investment of these new resources.

Step I10: This case study exhibits the benefits of implementing reconfigurable resources on an assembly line in a given industry. This showcase intends to benefit to the whole company, with the idea that any new definition of the assembly line should consider the reconfigurability aspects of the design phase.

\subsection{Additive Manufacturing for Optronics Parts}

This second study emphasizes the potential opportunities offered by switching to a new mode of mechanical design, namely a "Design By Additive Manufacturing" (DBAM), with an application in the aeronautics and defense fields. A global design approach in five steps, created as a modular framework, is suggested to be introduced in this new methodology [52]. The study was conducted by a team of designers from a financing company, composed of three people of various qualifications and experience.

Step I1: The main lever targeted in this study is to try and manage the complexity of assemblies as early as the design phase. If complexity is reduced, benefits are expected in terms of lower assembly costs and improvements to the reliability of final products.

Step I2: The technology identified to cope with this lever is additive manufacturing. This choice of technology has a direct impact on the design phase: a reliable design needs to be considered as soon as possible in terms of the way it will be manufactured in order to enhance the time to market of the product. A new manufacturing technology implies a major change in the way the parts are designed, and in this case on the whole design methodology.

Step I3: The study relies on a single part, denoted " 4 mirrors head". This choice was made because of the complexity of the assembly (five parts) relative to the small size of the product (about $1 \mathrm{dm}^{3}$ ). Being an embedded component of a mobile device, some design parameters, such as weight and stiffness for example, need to be as enhanced if possible. In the same way, over 20 different functions are defined for the final product or its direct neighborhood. The objective of the design is to increase the number of functions the final assembly can fulfill.

Step P4: The indicators defined in this step are quite simple: the number of components of the final assembly to optimize the main lever, number of functions fulfilled by the assembly, weight, and stiffness to optimize its embedded behavior and some other product performance criteria in order to validate its behavior in any circumstance.

Step P5: The team of designers created a first assembly, manufactured using classical machining. This product was composed of five components and was able to fulfill 16 functions at $260 \mathrm{~g}$. This was chosen as the lower bound of the study, as it was the result of the best performance from the engineers of the company with the tools at their disposal before additive manufacturing.

Step P6: This step is not documented in this study. During design processes, this is generally an implicit step, performed in parallel with an evaluation of the functional requirements specifications. The optimal solution is a virtual assembly of the only material 
necessary to achieve the expected functionalities, without considering the physical or technological constraints necessary for the use or manufacture of the product.

Step S7: This step is mostly built around the use of the DBAM methodology: knowledge synthesis, product specification, concept generation, control, and finally design and evaluation using computer-aided design. A design loop for topological optimization, using a Finite element simulation, was also used in order to generate the shapes for the best compromise between weight and stiffness. The result is a single part, fulfilling 20 functions, at a weight of $245 \mathrm{~g}$.

Step S8: The simulation phase was developed by making some prototype parts in SLA and polymer. These prototypes were designed to evaluate the notions of ergonomics and perform some mountability tests. The reliability aspect was not explicitly tested. These prototypes also validated the coherence between CAD-defined shapes and actual shapes obtained by additive manufacturing with this specific design.

Step I9: The preparation of implementation was performed thanks to the first prototypes of the final part on the actual machine, made in SLM and aluminum AS7G06. In addition to the validation of the manufacturing process, it also enabled to deal with accessory (but mandatory) aspects, such as the elimination of supports, heat treatment, or painting. From these prototypes, it the required reconfiguration of the assembly process with these new tasks was also decided.

Step I10: The implementation of additive manufacturing in this company implied a major change in the way the parts need to be designed. An innovative design framework was therefore integrated in the design office in order to capitalize on this experience for further projects, including re-designing some former assemblies.

\subsection{Holonic Manufacturing System for Distribution Systems}

The last study deals with mail distribution centers of the French national postal service, La Poste [53]. Every day, human operators need to handle about 30,000 containers full of mail per center (about $12 \mathrm{~kg}$ each) to distribute them to the right carts before they are placed in trucks. One of the objectives of the digital transformation of the company was to robotize this task in order to decrease its impact on operator health. To be efficient, it is therefore necessary to optimize the distribution of containers and carts towards the robots in order to maximize the load no longer handled by the operators [54].

Step I1: The major problem facing the distribution centers is the unpredictability of mail arrival. It is customary to say that the centers suffer the arrival of mail rather than control it. Even if some patterns can be identified, the variability between two "similar" days is too important. The lever identified here is the variability in the demand. In addition, many disturbances appear all along the year, which have a similar impact on disorganizing the distribution process (traffic problems, weather variability, etc.).

Step I2: The paradigm that was identified here is the multi-agent paradigm, and holonic manufacturing systems in particular. The notion of an agent is very well suited for adapting to the variability of an input, but the emerging behavior makes the guarantee of performance difficult to evaluate; thus, the difficulty of introducing this notion in industry.

Step I3: The ultimate objective of the digital transformation of the distribution centers is to implement this paradigm in the whole center, interconnecting all the sub-systems. This study started with the implementation of the "Flexibac" system, i.e., a pick and place robotic system aiming at handling mail containers. Therefore, the study only focuses on the integration of this system on the main transitic loop, in parallel with the conveyors occupied by the operators.

Step P4: The KPIs of this study are related to the number of containers handled by Flexibac. In parallel, the filling rate of the carts is measured, as it is connected to the number of cart movements made by the operators. These KPIs were evaluated in the execution over several days, chosen by the experts as typical days. The input of each scenario contains a timestamp of arrival for each container in the system to be handled. 
Step P5: The evaluation of the lower bound of the performance was made in the simulation of a virtual implementation of Flexibac. In this model, the knowledge of the experts was formalized in order to determine the best organization currently implementable with the available computer infrastructure. It was designed as an evolution of the daily plans that are currently in use in those centers.

Step P6: The upper bound was made using operational research techniques. The objective was to determine the optimal schedule of carts and containers to send to Flexibac in order to optimize the KPI. The results that were obtained necessitated adding several hypotheses to simplify the problem, which included the necessity to suppress the input variability: the scheduler needed the knowledge of the incoming containers of the whole day to really be able to optimize the distribution [54]. The schedule was tested on simulations of different days and showed low results, which confirmed the impossibility of implementing this solution. However, the level of the KPI (about four times better than the lower bound) provides a clear upper bound that will be almost unreachable for any other solution.

Step S7: The solutions that were designed were based on heuristics. The experts of the system were interviewed to gather their opinions about a first version of the optimal behavior they imagined. Based on their answers, a rule-based behavior of the system was designed. Rules were enacted for the containers, for the entrance for Flexibac, for Flexibac itself, and for the cart changing device of Flexibac.

Step S8: The rules were programmed inside a Flexsim simulation model to evaluate their pertinence. Obviously, this first version probably constitutes a draft version of the rules that will be actually applied to the system, as it does not consider some of the possible disturbances (machine breakdowns for example), but the objective was to have an evaluation of the nominal performance of the control system. The results were globally in the middle, between the lower and the upper bounds, which was above the estimations of the experts.

Step 19: The preparation of the implementation was made by the programming of a holonic-based control system, based on a multi-agent system (Jade). The objective of this program was to demonstrate how such rules could be applied on the targeted distributed system. Indeed, the simulation models' behavior greatly differs from the actual control programs. One of the major examples of these differences is the handling of time during calculations: in the simulation, the clock is stopped, whereas time never stops in multi-agent systems nor in reality.

Step I10: The long-term objective of the company is to better handle major disturbances in the distribution systems, in addition to the unpredictability of the inputs of the system. To this end, the holonic paradigm constitutes a coherent choice, as its innate scalability features enable to develop a growing set of interconnected systems in the near future. The first step of the integration of Flexibac is, therefore, the first step towards a large-scale application of the multi-agent paradigm in the control of distribution centers, and constitutes a major shift in comparison with the rigid plans currently used.

\section{Conclusions}

This article intends to provide a generic answer to a current concern that is widely spread in both academic and industrial contexts. When dealing with innovative Industry 4.0 technologies, there is a lack of generic methodological frameworks to support practitioners in their effort of implementation. The suggested framework, denoted as IPSI, consists in 10 steps, from objective definition to actual implementation, through simulation evaluation and solution prototyping. This framework was established thanks to a systematic literature review that highlighted the main features of the framework that should be incorporated. It was then confronted by three successful implementations, published in the literature, to confirm its validity. The studies were chosen from various fields (namely a multi-agent paradigm, reconfigurable manufacturing systems and additive manufacturing) in order to also validate its applicability to different domains. The results of the applications of the 
IPSI framework to those case studies show a perfect adequation with the methodology expressed by the authors, highlighting the value of the framework. IPSI is meant to become an actual guideline for future solution developers.

This framework was designed for initial implementation of a new Industry 4.0 technology in a company. The idea is to gain benefit of the scalability of the solutions in order to be able to get a first result on a system with a relatively reasonable size (and investments impact) before generalizing the technology. Future research will therefore be led in two directions. First, it is necessary to evaluate if this framework is still valid for technology in which the company has a high degree of maturity. Second, the framework needs to be extended to a second stage of generalization of the technology in a whole company, including the possibility of fostering the implementation of related new technologies during the generalization of the first technology. This extension would encompass the logic of continuous improvement highlighted by the current lean approaches.

Funding: This research received no external funding.

Conflicts of Interest: The author declares no conflict of interest.

\section{References}

1. Cardin, O.; Ounnar, F.; Thomas, A.; Trentesaux, D. Future industrial systems: Best practices of the intelligent manufacturing and services systems (IMS2) French research group. IEEE Trans. Ind. Inform. 2016, 13, 704-713. [CrossRef]

2. Heng, S. Industry 4.0: Not Alone an Issue for Computer Scientists; Social Science Research Network: Rochester, NY, USA, 2019.

3. Basl, J. Pilot study of readiness of Czech companies to implement the principles of industry 4.0. Manag. Prod. Eng. Rev. 2017, 8, 3-8. [CrossRef]

4. $\quad$ Ezell, S.J.; Atkinson, R.D.; Kim, I.; Cho, J. Manufacturing Digitalization: Extent of Adoption and Recommendations for Increasing Penetration in Korea and the U.S.; Social Science Research Network: Rochester, NY, USA, 2018.

5. Tlegenov, Y.; Hawkridge, G.; McFarlane, D.; Parlikad, A.K.; Reyner, N.J.; Thorne, A. Low cost monitoring on a shoestring: Solutions for digital manufacturing. IFAC-PapersOnLine 2020, 53, 10342-10347. [CrossRef]

6. Hawkridge, G.; Schönfuß, B.; McFarlane, D.; de Silva, L.; Terrazas, G.; Salter, L.; Thorne, A. Towards shoestring solutions for UK manufacturing SMEs. In Proceedings of the Companion of the 2020 ACM/IEEE International Conference on Human-Robot Interaction, Cambridge, UK, 23 March 2020; p. 72.

7. McFarlane, D.; Ratchev, S.; Thorne, A.; Parlikad, A.K.; de Silva, L.; Schönfuß, B.; Hawkridge, G.; Terrazas, G.; Tlegenov, Y. Digital manufacturing on a shoestring: Low cost digital solutions for SMEs. In Service Oriented, Holonic and Multi-Agent Manufacturing Systems for Industry of the Future; Borangiu, T., Trentesaux, D., Leitão, P., Giret Boggino, A., Botti, V., Eds.; Springer International Publishing: Cham, Switzerland, 2020; pp. 40-51.

8. Tjahjono, B.; Esplugues, C.; Ares, E.; Pelaez, G. What does industry 4.0 mean to supply chain? Procedia Manuf. 2017, 13, 1175-1182. [CrossRef]

9. Moretti, E.D.A.; Anholon, R.; Rampasso, I.S.; Silva, D.; Santa-Eulalia, L.A.; Ignácio, P.S.D.A. Main difficulties during RFID implementation: An exploratory factor analysis approach. Technol. Anal. Strat. Manag. 2019, 31, 943-956. [CrossRef]

10. Rüßmann, M.; Lorenz, M.; Gerbert, P.; Waldner, M.; Justus, J.; Engel, P.; Harnisch, M. Industry 4.0: The Future of Productivity and Growth in Manufacturing Industries; Boston Consulting Group. 2015. Available online: https://inovasyon.org/images/ Haberler/bcgperspectives_Industry40_2015.pdf (accessed on 15 September 2021).

11. Ciano, M.P.; Dallasega, P.; Orzes, G.; Rossi, T. One-to-one relationships between Industry 4.0 technologies and lean production techniques: A multiple case study. Int. J. Prod. Res. 2020, 59, 1386-1410. [CrossRef]

12. Culot, G.; Nassimbeni, G.; Orzes, G.; Sartor, M. Behind the definition of Industry 4.0: Analysis and open questions. Int. J. Prod. Econ. 2020, 226, 107617. [CrossRef]

13. Liao, Y.; Deschamps, F.; Loures, E.D.F.R.; Ramos, L.F.P. Past, present and future of Industry 4.0-A systematic literature review and research agenda proposal. Int. J. Prod. Res. 2016, 55, 3609-3629. [CrossRef]

14. Machado, C.G.; Winroth, M.P.; Da Silva, E.H.D.R. Sustainable manufacturing in Industry 4.0: An emerging research agenda. Int. J. Prod. Res. 2019, 58, 1462-1484. [CrossRef]

15. Núñez-Merino, M.; Maqueira-Marín, J.M.; Moyano-Fuentes, J.; Martínez-Jurado, P.J. Information and digital technologies of Industry 4.0 and lean supply chain management: A systematic literature review. Int. J. Prod. Res. 2020, 58, 5034-5061. [CrossRef]

16. Vaidya, S.; Ambad, P.; Bhosle, S. Industry 4.0-A glimpse. Procedia Manuf. 2018, 20, 233-238. [CrossRef]

17. Rossini, M.; Costa, F.; Tortorella, G.; Portioli-Staudacher, A. The interrelation between Industry 4.0 and lean production: An empirical study on European manufacturers. Int. J. Adv. Manuf. Technol. 2019, 102, 3963-3976. [CrossRef]

18. Cadavid, J.P.U.; Lamouri, S.; Grabot, B.; Pellerin, R.; Fortin, A. Machine learning applied in production planning and control: A state-of-the-art in the era of industry 4.0. J. Intell. Manuf. 2020, 31, 1531-1558. [CrossRef] 
19. Fragapane, G.; Ivanov, D.; Peron, M.; Sgarbossa, F.; Strandhagen, J.O. Increasing flexibility and productivity in Industry 4.0 production networks with autonomous mobile robots and smart intralogistics. Ann. Oper. Res. 2020, 1-19. [CrossRef]

20. Rodič, B. Industry 4.0 and the new simulation modelling paradigm. Organizacija 2017, 50, 193-207. [CrossRef]

21. Munirathinam, S. Chapter six-Industry 4.0: Industrial internet of things (IIOT). Adv. Comput. 2020, 117, 129-164.

22. Borangiu, T.; Trentesaux, D.; Thomas, A.; Leitão, P.; Barata, J. Digital transformation of manufacturing through cloud services and resource virtualization. Comput. Ind. 2019, 108, 150-162. [CrossRef]

23. Dilberoglu, U.M.; Gharehpapagh, B.; Yaman, U.; Dolen, M. The role of additive manufacturing in the era of industry 4.0. Procedia Manuf. 2017, 11, 545-554. [CrossRef]

24. Rani, N.A.; Aziz, F.A.; Hairuddin, A.A.; Ahmad, S.A.; Hemdi, A.R. Augmented reality: Capabilities and challenges in machining industry aligned with industry 4.0. Adv. Mater. Process. Technol. 2020, 1-9. [CrossRef]

25. Da Xu, L.; Xu, E.L.; Li, L. Industry 4.0: State of the art and future trends. Int. J. Prod. Res. 2018, 56, 2941-2962. [CrossRef]

26. Moeuf, A.; Lamouri, S.; Pellerin, R.; Tamayo, S.; Tobon-Valencia, E.; Eburdy, R. Identification of critical success factors, risks and opportunities of industry 4.0 in SMEs. Int. J. Prod. Res. 2019, 58, 1384-1400. [CrossRef]

27. Sakurada, L.; Geraldes, C.A.S.; Fernandes, F.P.; Pontes, J.; Leitão, P. Analysis of new job profiles for the factory of the future. In International Workshop on Service Orientation in Holonic and Multi-Agent Manufacturing; Springer: Cham, Switzerland, 2021; Volume 952, pp. 262-273. [CrossRef]

28. Brocke, J.; Simons, A.; Niehaves, B.; Niehaves, B.; Reimer, K.; Plattfaut, R.; Cleven, A. Reconstructing the giant: On the importance of rigour in documenting the literature search process. In Proceedings of the European Conference on Information Systems (ECIS), Verona, Italy, 8-10 June 2009.

29. Ouzzani, M.; Hammady, H.; Fedorowicz, Z.; Elmagarmid, A. Rayyan-A web and mobile app for systematic reviews. Syst. Rev. 2016, 5, 210. [CrossRef]

30. Veile, J.W.; Kiel, D.; Müller, J.M.; Voigt, K.-I. How to implement industry 4.0? An empirical analysis of lessons learned from best practices. In Proceedings of the Organizational, and Environmental Determinants, International Association for Management of Technology (IAMOT) Conference, Birmingham, UK, 22-26 April 2018; pp. 22-26.

31. Veile, J.W.; Kiel, D.; Müller, J.M.; Voigt, K.-I. Lessons learned from Industry 4.0 implementation in the German manufacturing industry. J. Manuf. Technol. Manag. 2019, 31, 977-997. [CrossRef]

32. Calabrese, A.; Ghiron, N.L.; Tiburzi, L. 'Evolutions' and 'revolutions' in manufacturers' implementation of industry 4.0: A literature review, a multiple case study, and a conceptual framework. Prod. Plan. Control. 2020, 32, 213-227. [CrossRef]

33. Hirman, M.; Benesova, A.; Steiner, F.; Tupa, J. Project Management during the industry 4.0 implementation with risk factor analysis. Procedia Manuf. 2019, 38, 1181-1188. [CrossRef]

34. Mittal, S.; Khan, M.A.; Purohit, J.; Menon, K.; Romero, D.; Wuest, T. A smart manufacturing adoption framework for SMEs. Int. J. Prod. Res. 2019, 58, 1555-1573. [CrossRef]

35. Frank, A.G.; Dalenogare, L.S.; Ayala, N.F. Industry 4.0 technologies: Implementation patterns in manufacturing companies. Int. J. Prod. Econ. 2019, 210, 15-26. [CrossRef]

36. Mahmoud, M.A.; Grace, J. A Generic evaluation framework of smart manufacturing systems. Procedia Comput. Sci. 2019, 161, 1292-1299. [CrossRef]

37. Mahmoud, M.A.; Grace, J. Towards the adoption of smart manufacturing systems: A development framework. Int. J. Adv. Comput. Sci. Appl. 2019, 10. [CrossRef]

38. Taurino, T.; Villa, A. A method for applying industry 4.0 in small enterprises. IFAC-PapersOnLine 2019, 52, 439-444. [CrossRef]

39. Lu, Y.; Liu, C.; Wang, K.I.-K.; Huang, H.; Xu, X. Digital twin-driven smart manufacturing: Connotation, reference model, applications and research issues. Robot. Comput. Manuf. 2019, 61, 101837. [CrossRef]

40. Dossou, P.-E. Development of a new framework for implementing industry 4.0 in companies. Procedia Manuf. 2019, 38, 573-580. [CrossRef]

41. Sadiq, S.; Amjad, M.S.; Rafique, M.Z.; Hussain, S.; Yasmeen, U.; Khan, M.A. An integrated framework for lean manufacturing in relation with blue ocean manufacturing-A case study. J. Clean. Prod. 2020, 279, 123790. [CrossRef]

42. Kusiak, A. Smart manufacturing. Int. J. Prod. Res. 2017, 56, 508-517. [CrossRef]

43. Chalfoun, I.; Kouiss, K.; Bouton, N.; Ray, P. Specification of a Reconfigurable and Agile Manufacturing System (RAMS). Int. J. Mech. Eng. Autom. 2014, 1, 387-394.

44. Kubler, S.; Derigent, W.; Thomas, A.; Rondeau, E. Embedding data on "communicating materials" from context-sensitive information analysis. J. Intell. Manuf. 2013, 25, 1053-1064. [CrossRef]

45. Maleki, E.; Belkadi, F.; Ritou, M.; Bernard, A. A Tailored ontology supporting sensor implementation for the maintenance of industrial machines. Sensors 2017, 17, 2063. [CrossRef] [PubMed]

46. Liu, X.F.; Shahriar, R.; Al Sunny, S.N.; Leu, M.C.; Hu, L. Cyber-physical manufacturing cloud: Architecture, virtualization, communication, and testbed. J. Manuf. Syst. 2017, 43, 352-364. [CrossRef]

47. Stock, T.; Obenaus, M.; Kunz, S.; Kohl, H. Industry 4.0 as enabler for a sustainable development: A qualitative assessment of its ecological and social potential. Process. Saf. Environ. Prot. 2018, 118, 254-267. [CrossRef]

48. Quintanilla, F.G.; Cardin, O.; L'Anton, A.; Castagna, P. A Petri net-based methodology to increase flexibility in service-oriented holonic manufacturing systems. Comput. Ind. 2016, 76, 53-68. [CrossRef] 
49. Antzoulatos, N.; Castro, E.; Scrimieri, D.; Ratchev, S. A multi-agent architecture for plug and produce on an industrial assembly platform. Prod. Eng. 2014, 8, 773-781. [CrossRef]

50. Eynaud, A.B.D.; Klement, N.; Gibaru, O.; Roucoules, L.; Durville, L. Identification of reconfigurability enablers and weighting of reconfigurability characteristics based on a case study. Procedia Manuf. 2019, 28, 96-101. [CrossRef]

51. Dit Eynaud, B.A. Design Approach for a Reconfigurable Assembly System, in a Context of Strong Market Variations in Terms of Volume and Product Diversity. Ph.D. Thesis, ENSAM, Paris, France, 2020.

52. Segonds, F. Design by additive manufacturing: An application in aeronautics and defense. Virtual Phys. Prototyp. 2018, 13, 237-245. [CrossRef]

53. Selma, C.; Tamzalit, D.; Mebarki, N.; Cardin, O.; Bruggeman, L.; Thiériot, D. Industry 4.0 and service companies: The case of the french postal service. In Service Orientation in Holonic and Multi-Agent Manufacturing; Borangiu, T., Trentesaux, D., Thomas, A., Cavalieri, S., Eds.; Studies in Computational Intelligence; Springer: Berlin/Heidelberg, Germany, 2018; Volume 803, pp. 436-447.

54. Selma, C.; Thevenin, S.; Mebarki, N.; Cardin, O.; Tamzalit, D.; Thiériot, D.; Bruggeman, L. Heuristics for robots-humans tasks assignment in a containers loading center. IFAC-PapersOnLine 2019, 52, 13-18. [CrossRef] 